\title{
Olfactory Recognition of Individual Competitors by Means of Faeces in Horse (Equus caballus)
}

Konstanze Krueger, Birgit Flauger

corresponding author: Konstanze Krueger: konstanze-krueger@equine-science.de

'The original publication is available at www.springerlink.com' 2011

Animal Cognition DOI: 10.1007/s10071-010-0358-1

\begin{abstract}
Living in complex social systems requires perceptual and cognitive capacities for the recognition of group membership and individual competitors. Olfaction is one means by which this can be achieved. Many animals can identify individual proteins in urine, skin secretions, or saliva by scent. Additionally, marking behaviour in several mammals and especially in horses indicates the importance of sniffing conspecifics faeces for olfactory recognition. To test this hypothesis, we conducted two separate experiments: Experiment one addressed the question of whether horses can recognize the group membership of other horses by sniffing their faeces. The horses were presented with four faecal samples: 1) their own, 2) those of other members of their own group, 3) those of unfamiliar mares, and 4) those of unfamiliar geldings. Experiment two was designed to assess whether horses can identify the group member from whom a faecal sample came. Here, we presented two groups of horses with faecal samples from their group mates in random distribution. As controls, soil heaps and sheep faecal samples were used. In experiment one, horses distinguished their own from their conspecifics' faeces, but did not differentiate between familiarity and sex. In experiment two, the horses from both groups paid most attention to the faeces of the horses from which they received the highest amount of aggressive behaviours. We therefore suggest that horses of both sexes can distinguish individual competitors among their group mates by the smell of their faeces.
\end{abstract}

\section{Keywords:}

equids, faecal samples, horse, olfaction, sociality

\section{Introduction}

Numerous animal species need to recognize their conspecifics. In dispersed social systems animals need to recognize their kin and their neighbours, or at least distinguish familiar from unfamiliar individuals for mating and habitat protection. Additionally, animals living in social systems require competences for the recognition of conspecifics, the formation of alliances, the discrimination of competitors and hierarchical access to resources (Wilson 1975). Such recognition has been described as being mediated through auditory, visual, and olfactory perception (Trillmich and Rehling 2006, Ligout and Porter 2006, Tibbets 2002). Olfactory recognition in particular plays an important role for a variety of social animals such as ants (Dreier et al. 2007), honey bees (Pesenti et al. 2008), insects in general (Howard and Blomquist 2005), sticklebacks (Mehlis et al. 2008), ringtailed lemurs (Scordato and Drea 2007), Belding's ground squirrels (Mateo 2006), rabbits (Patris et al. 2008), mice (Arakawa et al. 2008) and many other social mammals (Eisenberg and Kleiman 1972).

Generally kin recognition can be distinguished from mate choice. Kin recognition serves the detection of replicators, i.e. the discrimination of relatives that carry copies of recognition promoting alleles. Mate choice concerns genetically compatible or superior mating partners that may transmit beneficial genes to any offspring (Dawkins 1982). Our study deals with olfactory recognition of group members in horses that may include both kin recognition among related horses, and mate choice among mating partners. In the mate choice category we may also include the distinction of unrelated group members and of competitors for resources such as mates, food and social bonding.

For all olfactory recognition processes cues need to be produced by emitters and perceived by receivers. The scent cues can either be produced endogenously, for example by genes that express major histocompatibility complex proteins (MHC) and major urinary proteins (MUP) in mice (Penn and Potts 1998, Brennan 2004), or acquired from the environment, such as odorants which animals were exposed 
to as embryos (Waldman 1991). The receivers form internal representations of the scent characteristics, so called "templates", and recognition occurs when the perceived cue matches the template (Sherman et al. 2003). For all recognition processes specific templates have to be learned, especially when the same cue can differ in its meaning according to the emitting individual or the situation. For example, predator responses from vervet monkeys are judged differently when given from adults and offspring (Cheney and Seyfarth 1990). Learning is especially needed if the cues are emitted as a consequence of direct interactions, or when observing the interactions of others, or for learning the characteristics of desired or undesired emitters. Some templates are learned in early life (imprinted), and other templates have to be updated when their characteristics change over time, for example, when new competitors arrive at the territory borders of Grevy zebra stallions, (Klingel 1972), or group membership changes in feral horses (Tyler 1972, Berger 1977).

Equids are highly social animals, analogous with several mammals such as many primate species (Clutton Brock 1974), elephants (Moss and Poole 1983), hyenas (Smith et al. 2008), and dolphins (Connor et al. 2000). Behavioural data indicate that horses are capable of social cognition (Krueger and Heinze 2008), i.e. the processing, encoding, storage, retrieval, and application of social information, an ability which has previously been reported in primates, social birds and social ungulates (Veissier et al. 1998, Treichler and Van Tilburg 1996, Roberts et al. 1979, Acuna et al. 2002, Paz-y Miño et al. 2004, Allen 2006, Moses et al. 2006).

Horses live in relatively stable social units, called bands, family groups or harems (Klingel 1972, Moehlman 2005, see for review: Linklater 2000). Harems or bands number from two to about 25 horses, and usually consist of one to five stallions, with several mares and their offspring (Tyler 1972, Berger 1977, Moehlman 2002). Surplus stallions gather in bachelor bands (Berger 1977). It is still under discussion whether several subgroups form a large structured social unit, called a "herd", and show the same migration patterns within a common home range (Duncan 1992, Feh 2005) or whether a collection of subgroups should rather be termed a "population", which synchronize daily and seasonal patterns of movements in response to water, food, or climate (Feist and McCullough 1976, Berger 1986, Linklater et al. 1999) and show inter-band hierarchies at resource patches (Miller and Denniston, 1979, Franke Stevens 1988, see for review: Linklater 2000).

In these herds or populations a considerable number of inter-band movements have been reported, even though horse bands show stable core groups (Linklater et al. 2000, King 2002, King and Gurnell 2005). After most offspring have dispersed from their natal groups, usually by 5 years of age $(97 \%$ of males and $81 \%$ of females: Rutberg and Keiper 1993), adult horses have then frequently been observed to change groups. All-male "bachelor" bands have been described as instable in feral horse populations with only a few exceptions (Feist and McCullough 1976, Miller 1981, Berger 1986, Feh 1999, Feh 2001, see for review: Linklater 2000), and some temporary mixed sex peer groups have been observed (Keiper 1976, Linklater et al. 2000). Several authors also report the dispersal of adult mares from harems (fission: Rutberg 1990, Rutberg and Greenberg 1990, Berger 1986, Linklater and Cameron 2000) as well as their return (fusion: Goldschmidt-Rothschild and Tschanz 1978). Between all these groups and populations the harem or band stability varied considerably (Rutberg 1990, Berger 1986, Rubenstein 1986).

Such complex social systems require horses to memorize and generalize social experiences, distinguish between familiar and unfamiliar, and identify familiar horses, as well as recognize their social status relative to their own group (Krueger and Heinze 2008). Horses exhibit excellent long term memory of memberships of their own group (see for review: Nicol 2002, Murphy and Arkins 2007).

Several perceptual methods have been observed for social recognition in horses. They try to stay in contact through auditory cues (Feist and McCullough 1976, Kiley 1972, Tyler 1972, Feh 2005, Rubenstein and Hack 1992) and identify humans (Stone 2010) and their group members by sight (Feist and McCullough 1976, Tyler 1972, Feh 2005) as well as sound (Proops et al. 2009, Basile et al. 2009, Lemasson et al. 2009). Additionally, frequent sniffing of conspecifics as well as their faeces indicates the importance of olfaction in the horse's social recognition system (Feist and McCullough 1976, Tyler 1972, Stahlbaum and Houpt 1989, Feh 2005, Rubenstein and Hack 1992, Marinier et al. 1988, Saslow 2002).

Horses have the anatomical capacity for olfactory perception. Their noses can move large volumes of air in one breath and trap large numbers of molecules. Additionally, their nostrils are separated and point in different directions, which permits stereo-olfaction for localization (Stoddart 1980). Furthermore, Lindsay and Burton (1983) documented the existence of a prominent vomeronasal organ which is not required for, but may indicate, individual olfactory recognition in horses.

However, how horses identify their conspecifics by olfaction has rarely been investigated under controlled conditions (Saslow 2002). In many mammals olfactory recognition has been described as being mediated through urine, skin secretions, or saliva (e.g.: urine, mice: Penn and Potts 1998, elephants: Bates 2008; urine, skin secretions, or saliva, mice: Brennan 2004; preputial glands, mice: Lévy et al. 2004; mammalian social odours: Brennan and Kendrick 2006), but, inte- 
restingly, in marking behaviour in horses faeces and urine appear to be crucial (Kimura 2001, see for reviews: Eisenberg and Kleiman 1972, Gosling and Roberts 2001, Linklater 2000). As faeces evoke strong behavioural reactions, especially in stallions (Marinier et al. 1988, Stahlbaum and Houpt 1989, Kimura 2001, King and Gurnell 2005, see for review Linklater 2000), previous studies in horses analyzed stallion responses towards urine and faeces. Stallions were shown to be able to differentiate the sex (Stahlbaum and Houpt 1989) and the familiarity (Rubenstein and Hack 1992) of faecal donors. However, in urine samples, previous studies demonstrated the identification of neither the sex of the donor (Stahlbaum and Houpt 1989), nor the oestrus stage of female donors (Marinier et al. 1988, Kimura 2001).

A recent study (Hothersall et al. 2010) used pregnant mares and foals in a habituation-discrimination experiment using social cues of urine, faeces and body odour samples of unfamiliar horses. In line with earlier studies on social recognition in rodents (e.g. Thor and Holloway 1982) a basic social recognition paradigm was applied. With this technique the detection of conspecifics is demonstrated firstly by a high tendency to approach unknown conspecific's cues, secondly by the memorising of social cues as a result of repeated presentation (as indicated by a decline in the time spent sniffing the sample), and thirdly by the discrimination of memorised cues and their respective donors and new social cues (as indicated by an increased time spent sniffing the new cue). Hothersall et al. (2010) showed that the tested horses had already memorized the scent of other horses' urine, faeces and body odours at only the second presentation. When tested with urine samples horses appeared to discriminate between the sexes, but not between individuals among the unfamiliar horses.

For the present study we concentrated on recognition through olfactory perception in mares and geldings. Castration has been described as reducing sexual and aggressive but not other social behaviours (pigs: Rydhmer et al. 2010, ferrets: Vinke et al. 2008). Some ferrets even displayed more play behaviour in inter-male contact after castration (Vinke et al. 2008). In horses, surgical castration and immunocastration vary in their effects on mating behaviour, some geldings even retaining libido (surgical castration: Rios and Houpt 1995, immunocastration: Malmgren et al. 2001), but social investigation has been described to be less intense in geldings than in stallions (Hothersall et al. 2010). However, geldings integrate well into social horse groups and should be similarly capable of social olfactory perception. Additionally, for geldings the social interest in olfactory cues may outweigh reproductive interests.

The familiarity of the test horses may be crucial for individual discrimination (Proops et al. 2009, Hothersall et al. 2010). We therefore used horses that had been living in stable social groups for at least 6 months, as horses usually establish their dominance hierarchy within a few days (Waring 1983, Tilson et al. 1988), but rearrangements and stabilisation of the hierarchy may occur in the following weeks. The social groups for the present study numbered between 2 and 11 horses because such group sizes are commonly found in feral horse populations and are therefore not expected to exceed the horses' capacity for memorising group membership. In addition, we had used most of the horses in an earlier study (Krueger and Heinze 2008) in which they demonstrated behavioural responses of social recognition. The horses were of different breeds. As recent horse and pony breeds have been crossbred over the centuries, the horses' behaviour, especially their social behaviour and their sensory ecology was not expected to differ between breeds. Only Arabian horses have been kept "pure", but they have frequently been introduced into warmblood and pony breeds to upgrade the pedigree.

For this study we conducted 2 separate experiments. Experiment 1 (named: Social Experiment) tested the hypothesis that mares and geldings recognize their conspecifics' group membership through sniffing their faeces. For this experiment horses were confronted with their own faecal samples, with those of their group members, and with those of unfamiliar female and male horses. Experiment 2 (named: Individual Experiment) approached the hypothesis that mares and geldings can determine which member of their group was the donor of a faecal sample through olfactory recognition. Here we confronted horses with faecal samples from their group members in random distribution. As controls for both experiments we tested their behaviour towards visually similar samples of soil and faeces from different sheep.

\section{Methods}

Animals

We investigated the behaviour of 35 horses. They comprised 27 warm-blood horses and 6 ponies of mixed breeds, as well as 1 draught horse, and 1 thoroughbred horse. There were 23 mares and twelve geldings, and all were aged between 4 and 27 years. All horses were individually identified by their brands and colouring. Sleeping areas or boxes included bedding of straw or wood shavings. The daily feed of the horses consisted of hay twice a day, plus a compound feed three times a day for the boxed horses, and hay twice a day, plus a compound feed once a day for the open stable horses. In addition, they had access to grass on their pastures. Horses tested among each other were all similarly housed and fed.

Animals Social Experiment

25 horses from the same location were used for the Social Experiment. Most horses used for the Social 
Experiment $(\mathrm{N}=20)$ were kept in individual boxes overnight but turned out in 6 groups comprised of 2 , $2,2,3,5$ and 11 horses during the day time. One social group ( $\mathrm{N}=5$ ) was kept in open stabling day and night. In this group 2 horses were genetically related (mother-daughter relationship). The social groups for this experiment had not changed for at least 6 months. The particular social groups were not in physical contact with each other, and were not housed in adjacent stables, but they may have sniffed faces of other group members that were left at the stable aisle or cleaning areas.

Animals Individual Experiment

For the Individual Experiment 10 horses from 2 social groups (group 1: $\mathrm{N}=6$, group $2 \mathrm{~N}=4$ ) in 2 additional locations were used. They were kept in open stabling day and night. In group 1, 2 horses were genetically related (mother-daughter relationship). These social groups have been unchanged for 4 (group 1) and 2 (group 2) years.

\section{Faecal samples}

Prior to testing we picked up approximately 2 mugs worth of the freshest faecal samples from each of the test horses. We made use of the horses' habit of defecating after being fed and started collecting half an hour after feeding time. The faecal samples were all collected within one hour of each other. They were collected with unused plastic bags or one-way gloves and immediately tightly wrapped in the bags, to minimise the evaporation of volatile substances and to prevent any possible odour contamination from the collecting person.

\section{Experimental set-up}

Experiments were conducted in a clean riding area or in the clean feeding area of the open stable. In both cases faeces have always been immediately cleared away. Horses were confronted with 4 or 6 samples of faeces as described in the sub-item Social and Individual Experiment below. The faeces were randomly placed in a line, 1.5 meters apart from each other, and 6 meters away from the starting position (Fig. 1).

\section{Experimental set-up Social Experiment}

For the Social Experiment the horses were confronted with 4 dung heaps. The faecal samples were from the test horse itself, from another group member, from an unfamiliar male and an unfamiliar female horse.

\section{Experimental set-up Individual Experiment}

For the Individual Experiment, horses were confronted with as many dung heaps as there were members in the particular groups, i.e. their own faeces and faeces from each member of their own group. Thus faecal heaps numbered $\mathrm{N}=6$ for group 1 and $\mathrm{N}=4$ for group 2 .

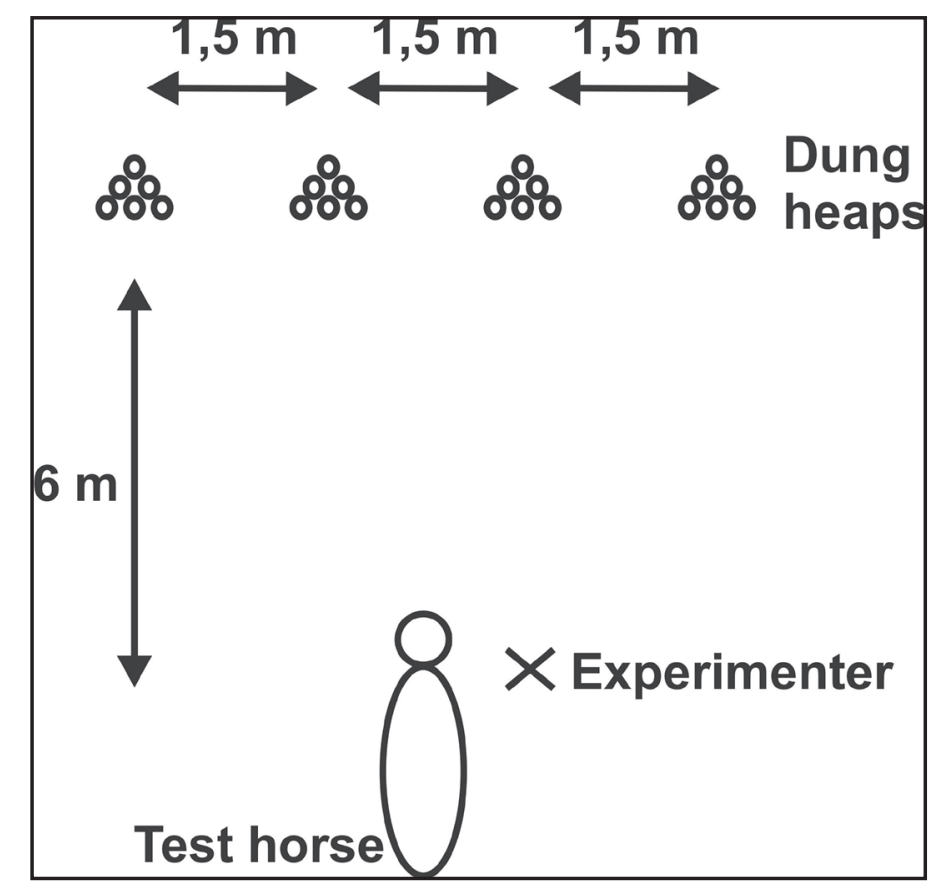

Fig. 1 Experimental set-up social and Individual Experiment. In the Social Experiment, all horses are confronted with four dung heaps (own, familiar, unfamiliar opposite sex, unfamiliar same sex); in the Individual Experiment, the number of dung heaps corresponds to the number of horses in the particular group (group 1: $\mathrm{N}=6$, group 2: $\mathrm{N}=4$ ). The depicted horse is standing in the starting position. The experimenter leaves the experimental area when the time count for the experiments starts

\section{Experimenters}

2 experimenters took part in the test phase. Experimenter 1 handled the horses and experimenter 2 placed the faecal samples in the experimental area in random order and then documented the responses of the horses from outside the experimental area with continuous video recording. She also wrote down the number, location, repetitions and order in which the respective faecal heaps were approached, as well as the sniffing times. Experimenter 1 was only partially blind; that is to say she did not know the order of the samples and left the experimental area, but re-entered the experimental area and led the horses to the samples they hadn't sniffed (for further explanations see: Experimental procedure). Experimenter 2 was blind; that is to say he/she was not visible to the horses in the Social Experiment. In the Individual Experiment, experimenter 2 was not visible to the horses of group 2. This was not possible for the horses of group 1. Therefore, experimenter 2 stayed in a distance of 20 meters to the experimental area, and did not face the horses, but recorded the horses' behaviour from the video screen.

\section{Experimental procedure}

Prior to the experiments, all the horses had regular access to the experimental area and were well habituated to the surroundings. After the faeces were 
randomly placed in a line, the horses were tested in random order. Each horse was led to the starting position by experimenter 1 , and the experimental area was closed. Then experimenter 1 released the horse and left the experimental area. The horses were given a predetermined time to move freely around in the experimental area and sniff at all the presented samples in whatever order, and for however long they chose within this time. The recording of sniffing time started from when the horses lowered their noses to $15 \mathrm{~cm}$ or closer to the pile, up until the noses left this range again. Finally, experimenter 1 led the horses out of the experimental area.

The individual horses differed in their propensity to approach the samples. To ensure that all horses had equal opportunities to show sniffing responses and to generate a reliable, comparable data set, it was necessary for experimenter 1 to re-enter the experimental area and lead the horses towards the heaps they had not voluntarily approached, and give them an extra 30 seconds to sniff at the respective samples if they chose to. When horses did not sniff at several samples they were led to them one by one at random, and given an extra 30 seconds at each sample. Experimenter 1 made sure not to face the particular sample but a predetermined fixed point opposite the sample line. Still we have to consider the possibility that the experimenter may have affected the horses' choices unconsciously, as horses are known to react on subtle human mimic and gestural cues (Pfungst 1907). Each of the horses required extra leading at some time during the experimental procedure. On average, the horses needed to be lead to $34 \%(S D=18 \%)$ of the equine faecal heaps, $23 \%$ $(S D=24 \%)$ of the soil heaps, and $29 \%(S D=21 \%)$ of the sheep faeces. The horses were not forced to sniff at the samples. Thus, the extra leadings did not necessarily result in sniffing responses from the horses. When the horses were lead to the 34\% (SD = $18 \%$ ) of equine faecal heaps they sniffed at $16 \%$ (SD $=11 \%)$ of the heaps, when lead to $23 \%(\mathrm{SD}=24 \%)$ of the soil heaps they sniffing at $9 \%(S D=13 \%)$ of the soil samples, and when lead to $29 \%(S D=21 \%)$ of the sheep faeces they sniffed at $22 \%(S D=15 \%)$ of the sheep samples. If they did not choose to sniff after being led to the pile, the behavioural reaction was counted as " 0 ".

\section{Duration Social Experiment}

In the Social Experiment all horses were given $2 \mathrm{mi}-$ nutes each to sniff at the 4 dung heaps.

\section{Duration Individual Experiment}

In the Individual Experiment the time allowed for sniffing the dung heaps was adjusted to the number of presented dung heaps, allowing 30 seconds for each heap. Thus group 1 has the opportunity to sniff 6 dung heaps and was given 3 minutes, group 2 was presen- ted with 4 dung heaps and was given 2 minutes.

Repetition Individual Experiment

The Individual Experiment was repeated 10 times over 21 days to cover the oestrus cycle of the participating mares.

\section{Control samples and control procedure}

Two control experiments, with soil and with sheep faeces instead of horse faeces, were conducted using the horses from the Individual Experiment.

Control visual cues

To control for a possible visual orientation of the test horses while sniffing at faeces, we conducted a control experiment in which we replaced the faecal samples with soil heaps. As the horse's visual acuity is limited (Timney and Keil 1992) it may be attracted by visual cues from the faecal heaps such as size, shape and colour. The test horses were therefore confronted with as many soil samples of similar size, shape and colour as in the previous faecal sample experiment.

\section{Control olfactory cues}

Additionally, we controlled for other olfactory cues generally present in faecal samples, such as fatty acids, alcohols, aldehydes, phenols, amines and alkanes, and for a possible effect of the sample's position. To do this we replaced the horses' faecal samples with samples of fresh sheep faeces, each sample from a different sheep, in similar manner to the soil samples before.

\section{Control procedure}

In both control experiments the experimental set-ups and experimental procedures were the same as in the main experiment. The number of samples was adjusted to the number of members in the particular groups (group 1: $N=6$; group 2: $N=4$ ) and the quantities of the samples were matched to the horse faecal samples. Therefore, for the sheep, several faecal quantities were taken from the same animal to make up one sample. In contrast to the main experiments, both control situations were only tested once, so the samples remained in a constant position. Therefore, the position of the sheep faecal samples corresponded to the identity of the respective sheep.

\section{Dominance relationships}

Before starting the Individual Experiment, we determined the dominance relationships among the horses by observing agonistic encounters in the field, such as approaches, retreats, threats to bite or kick, bites, kicks and chases (McDonnell 2003, Mc Donnell and Haviland 1995, Feist and McCullough 1976). The horses were observed over 6 hours on separate days (at least 3 different days, with a minimum duration of $30 \mathrm{~min}$. and a maximum of $150 \mathrm{~min}$. each). 
Table 1
Dominance hierarchies

for test horses,

Individual Experiment

\begin{tabular}{|l|l|l|l|l|l|l|}
\hline & Age & Sex & Breed & Related & ADI score & Rank \\
\hline Group 1 & & & & & & \\
\hline Billy (Bi) & 18 & Gelding & Warm-blood & No & 0.827 & 1 \\
\hline Sara (Sa) & 22 & Mare & Haflinger & No & 0.732 & 2 \\
\hline Farina (Fa) & 23 & Mare & Warm-blood & No & 0.684 & 3 \\
\hline Peppermint (Pe) & 14 & Gelding & Pony & No & 0.367 & 4 \\
\hline Alexia (Al) & 6 & Mare & Haflinger & Mother & 0.204 & 5 \\
\hline Anouschka (An) & 20 & Mare & Haflinger & Daughter & 0.186 & 6 \\
\hline Group 2 & & & & & & \\
\hline Francis (Fr) & 13 & Mare & Warm-blood & No & 0.895 & 1 \\
\hline Traum (Tr) & 14 & Mare & Warm-blood & No & 0.635 & 2 \\
\hline Miss Lala (Mi) & 27 & Mare & Pony & No & 0.316 & 3 \\
\hline La Belle (La) & 14 & Mare & Pony & No & 0.154 & 4 \\
\hline
\end{tabular}

Observation periods had to be adjusted to accommodate the horses' commitments as riding horses, but were distributed over daylight hours. The interactions of the horses were recorded continuously. For the calculation of the individual dominance scores (table 1) we used an average dominance index (ADI) method. The ADI is calculated as follows: The dominance index per pair of individuals, $w$ ij is the number of times an individual won against or attacked a certain opponent divided by the total number of agonistic interactions in which the pair was involved with each other, thus $w i j=x i j /(x i j+x j i)$. If a pair of individuals was not involved in agonistic interactions with each other, it was excluded from the analysis. The average dominance index of an individual is the average of all its dominance indices with all its interaction partners, thus $1 / \mathrm{N} \Sigma \mathrm{j}$ wij. A higher value indicates a higher dominance in the group (Hemelrijk et al. 2005).

\section{Statistics}

Statistical analysis, as well as the depiction of the data, was done with the statistical software SPSS 17 and the R-Project statistical environment (2010). All tests used were two-tailed and the significance level was set at 0.05 . We analysed the frequencies with which horses sniffed the faeces by applying binomial tests, by comparing the number samples that were sniffed to the number of those that were not sniffed in the Social and Individual Experiment. For further comparison we equalized the individual habits of the horses by converting the time each horse spent sniffing each pile of faeces to percentages, i.e. we divided each horse's sniffing time on each sample in one trial multiplied by $100 \%$ by the total time spent sniffing in this trial. Then we derived the individual percentage of sniffing time the horses spent at each particular donor's faeces by adding the sniffing responses of the 10 experiment days and dividing them by the number of test days (i.e. 10). For the Social Experiment the KS-tests showed the data to be consistent with a normal distribution. Subsequently, we applied General Linear Models (GLM), for multivariate testing for any possible effect of gender and age, and for the comparison of the main behavioural data sets. The data of the Individual Experiment and its two control experiments were analysed with Generalized Linear Models (abbreviated: GizedLM) (Nelder and Wedderburn 1972, McCullough and Nelder 1989), which are models for parameter estimation for continuous or categorical response variables with distributions other than parametric. We continued our analysis for the Individual Experiment by comparing the sniffing responses the horses received from their group mates and the aggressive behaviour horses displayed among each other. For the Individual Experiment's group 1, in which the respective group members showed no significant differences in sniffing responses, we tested the hypothesis that individual levels of aggressive behaviour displayed among particular pairs of horses may correlate with individual sniffing responses. For the Individual Experiment's group 2, in which particular horses received significant sniffing responses, and which had one particularly aggressive horse, we compared the total amount of aggressive behaviour horses displayed towards specific group members with the received total amount of sniffing responses. We did this by applying multifactorial GizedLMs, with the donor's identity as factors.

\section{Results}

\section{Approaching and sniffing faeces}

Horses always sniffed the faeces they approached, but they varied in the time they sniffed at the particular samples. In general, the mares and geldings in this study were highly motivated to pay attention to faecal samples and used the opportunities to approach and sniff the faeces significantly above the chance level of $50 \%$ (Social Experiment, Binomial-Test: $n=100, p<$ 0.001; Individual Experiment, Binomial-Test: $\mathrm{n}=520$, $p<0.001)$. In the Social Experiment they approached and sniffed their own faeces, those of familiar horses, and those of unfamiliar horses from the opposite and the same sex equally (all: Binomial-Tests: $n=25, p<$ 
0.001). During the 10 repetitions of the Individual Experiment their interest did not significantly decrease and the experiment days, i.e. the trial number, did not have any effect on the approaches and sniffing times (GLM, experiment-day: $n=530, t=0.13, p=0.89$ ).

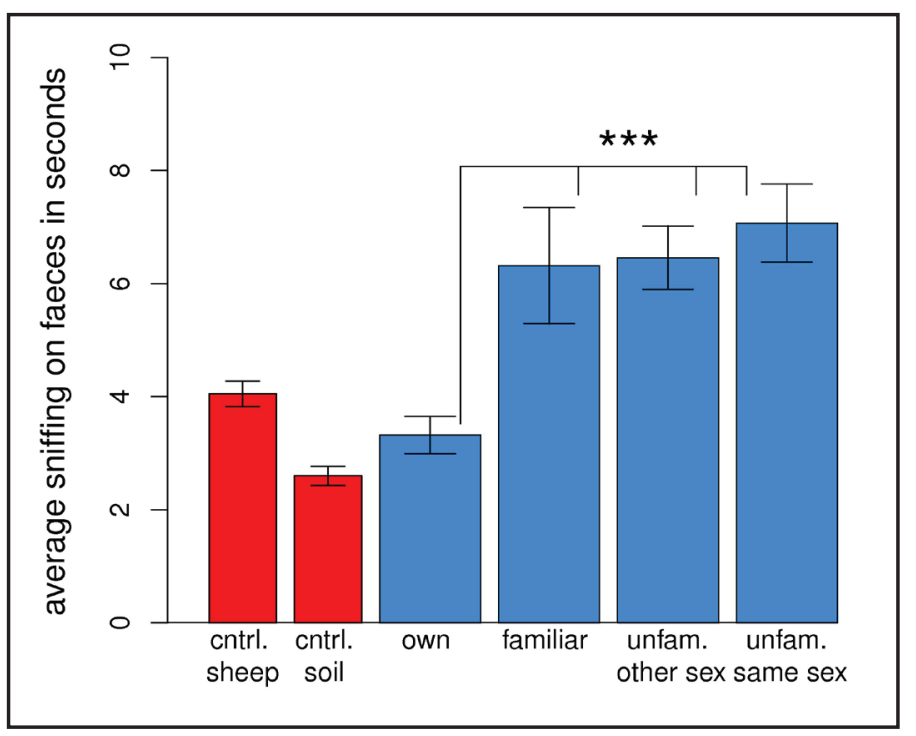

Fig. 2 SniYng times Social Experiment. This Wgure depicts the average of the horses' sniYng times at the samples in the Social Experiment and in the two control experiments. SniYng responses to familiar horses' faeces, and those of unfamiliar horses of the opposite and same sex signiWcantly diVer from those on own faeces. ***SigniWcant deviations from sniYng own faeces for $P<0.001$. Error bars depict the SEM

\section{Social Experiment}

General effects on sniffing time

For the Social Experiment we evaluated whether horses paid different amounts of attention to the faeces depending on the donor's group membership, age and sex. We measured the amount of time horses sniffed their own faeces, their group members' faeces, and unfamiliar faeces from horses of the opposite and of the same sex. In all data the age and gender of the test horses did not have any significant effect (GLM, age: $\mathrm{N}=25, \mathrm{t}=-0.76, \mathrm{p}=0.46$; sex: $\mathrm{N}$ $=25, \mathrm{t}=0.41, \mathrm{p}=0.69$ ).

Comparison between own faeces, faeces from familiar horses, unfamiliar horses of opposite sex and unfamiliar horses of same sex

Horses sniffed their own faeces least (mean sniffing time 3 sec., SD $=3$ sec., $15 \%$ of total sniffing time, Fig. 2). The mean sniffing time at their own faeces differed significantly from the sniffing times at faeces from familiar group members (GLM: $t=-642.06, p<$ 0.001 ; mean sniffing time 6 sec., SD $=10$ sec., $27 \%$ of total sniffing time), those of unfamiliar conspecifics of opposite sex (GLM: $t=-684.42, p<0.001$; mean sniffing time $6 \mathrm{sec}$., SD $=5 \mathrm{sec}$., $28 \%$ of total sniffing time) and those of unfamiliar conspecifics of same sex (GLM: $t=-625.08, p<0.001$; mean sniffing time $7 \mathrm{sec}$., SD $=7 \mathrm{sec}$., $30 \%$ of total sniffing time,). However the sniffing time spent on faeces of familiar horses and those of unfamiliar horses of opposite sex and same sex did not significantly differ between the samples (GLM, familiar - unfamiliar opposite sex: $t$ $=-1.80, p=0.09$; familiar - unfamiliar same sex: $\mathrm{t}=$ -1.02, $p=0.32$; unfamiliar opposite sex - unfamiliar same sex: $t=-1.80, p=0.08$ ).

Individual Experiment

General effects on sniffing time

For the Individual Experiment, we investigated whether horses would discriminate between the faeces of their own group members. In a general comparison, we found that the identity of the faecal sample's donor caused a significant difference in sniffing time (GizedLM: $N=520, t=425, p<0.001$ ), but none of the other possible effects on the sniffing time, such as the experiment day (GizedLM: $\mathrm{n}=520, \mathrm{t}=-0.13$, $\mathrm{p}$ $=0.89$ ), the position of the faeces (GizedLM: $n=520$, $t=1.42, p=0.16)$, or the order in which the faecal samples were collected (GizedLM: $n=520, t=1.1, p$ $=0.27$ ) were significant.

\section{Group 1: Sniffing responses}

When analysing the duration of horses sniffing their group members faeces, in group 1, none of the particular donors faeces was sniffed significantly longer than any other of their group mates (GizedLM: $n=$ $160, t=1.208, p=0.23$, Fig. $3-1 a)$.

Group 1: Sniffing responses versus individual aggressive behaviour

Differences did occur on an individual level when comparing the aggressive behaviour horses displayed towards each other and the sniffing responses they received from their group mates. In group 1, we compared individual sniffing responses with individual levels of aggressive behaviour displayed among particular pairs of horses. The pair-wise comparison between aggressive behaviour displayed and sniffing responses received was significant at the group level (GizedLM: $n=30, t=2.673, p=0.01$, Fig. 3-1b). When analysing for pair wise linear relationships between the sniffing responses received and aggressive behaviour displayed for particular horses, the results for Farina (GizedLM: $t=2.337, p=0.03$ ), Alexia (GizedLM: $t=3.360, p=0.003$ ), and Sara (GizedLM: $t=2.505, p=0.02$ ) were significant, for Billy (GizedLM: $t=1.937, p=0.06$ ) and Peppermint (GizedLM: $t=1.908, p=0.06)$ nearly significant, but not significant for Anouschka (GizedLM: $t=1.313, p=0.2$ ). 

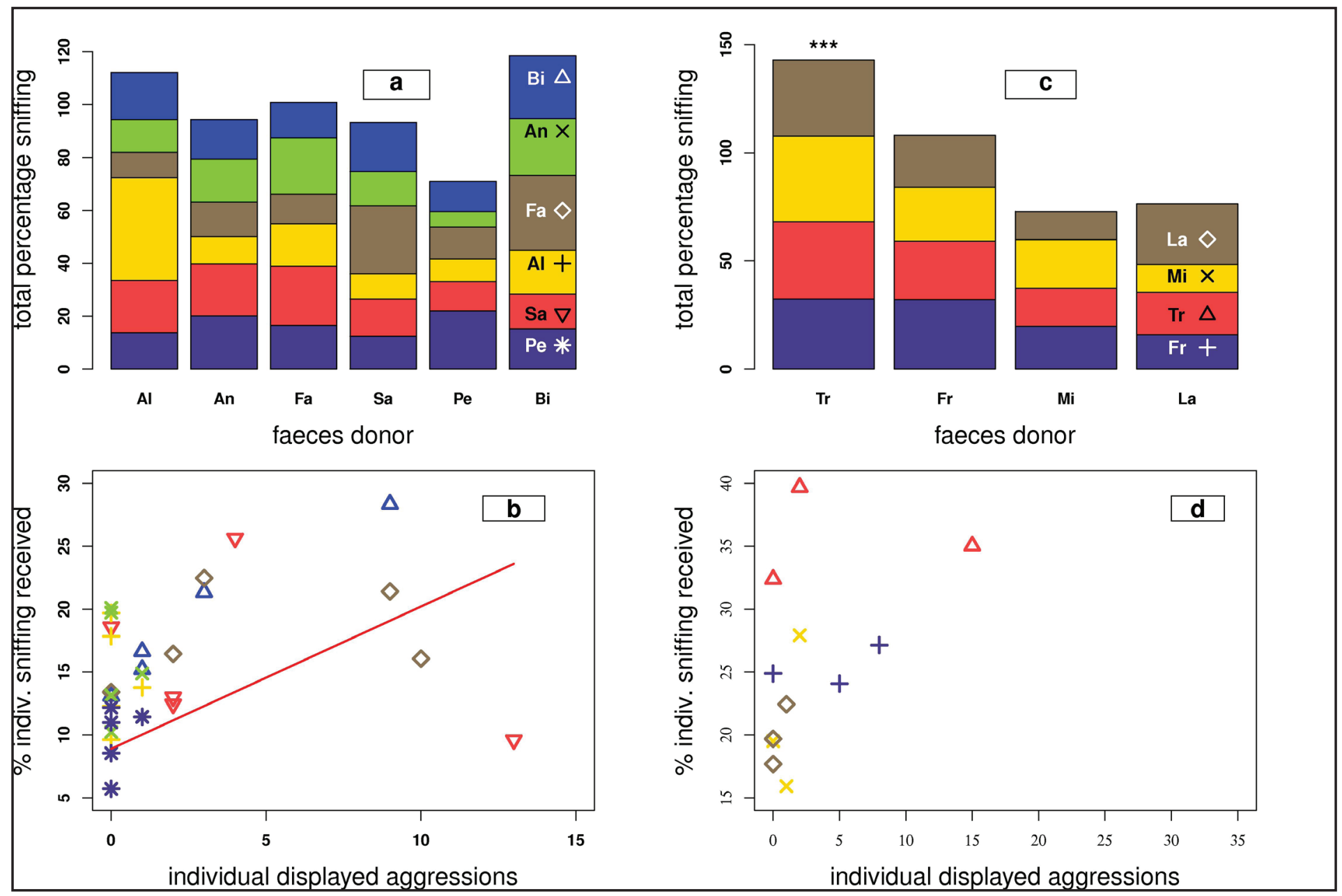

Fig. 3 Sniffng times Individual Experiment. The upper graphs a (group 1) and c (group 2) depict the respective donor's faeces listed on the x-axis and the piled up total percentages of sniffng durations the test horses received from their group members on the y-axis. The horses' identities are abbreviated in the last column of $a$ and $c$ (Table 1) and symbols of panels $b$ and $d$ associated. ${ }^{* *}$ Signiffcance for Traum $(P<0.001)$. The lower graphs b (group 1) and d (group 2) depict the linear re-

Group 2: Sniffing responses

In group 2 the horses significantly sniffed at particular group members' faeces (GizedLM: $n=160$, $t=3.34$, $p<0.001$, Fig. 3-2a).

Group 2: Sniffing responses versus total aggressive behaviour

For group 2 the level of received sniffing responses received showed a significant linear relationship to the total number of displayed aggressions towards particular horses (GizedLM: $\mathrm{n}=16, \mathrm{t}=5.758, \mathrm{p}<$ 0.001). One particular horse (Traum) significantly displayed the most aggressive behaviour and also received the significantly highest amounts of sniffing responses (GizedLM: $t=5.958, p<0.001$ ).

\section{Control visual cues}

In the visual control experiment horses sniffed the soil heaps for 3 seconds ( $S D=2.5$ sec.) on average. No horse showed a significant sniffing response to

lationship of received, individual sniYng durations and displayed individual aggressions from particular horses, which is signiffcant for group 1 on the group level $(P=$ 0.01 ). In group 2 , a positive linear relationship between received sniffng duration and displayed aggressions is again true for Traum $(P<0.001)$, but not for the whole group. Note that the sniffng on own faeces has been excluded from the comparison since horses cannot display aggressions against themselves

any of the particular soil heaps, nor did the horses' sniffing duration significantly differ with the heap positions, i.e. the specific samples (GizedLM: $n=52, t=$ 1.39, $p=0.17$ ). Sniffing soil heaps did not differ from sniffing at own faecal samples in the Social Experiment (GizedLM: $X^{2}=2.01, p=0.16$ ).

\section{Control olfactory cues}

In the olfactory control experiment horses sniffed the sheep faeces for 4 seconds (SD $3 \mathrm{sec}$.) on average. The sniffing durations for the sheep faeces position, and thus the respective sheep donors' identity, did not vary (GizedLM: $n=52, t=-0.13, p=0.9$ ). Sniffing sheep faeces did not differ from sniffing at own faecal samples in the Social Experiment (GizedLM: $X^{2}=0.9$, $p=0.34)$. 


\section{Discussion}

As expected from the horse's social structure (Klingel 1972, Tyler 1972, Berger 1977, Linklater 2000, Feh 2005, Moehlman 2002) and its frequently observed marking behaviour (Linklater 2000, Kimura 2001, King and Gurnell 2007), we conclude that the mares and geldings in this study are highly motivated to sniff faeces. They consistently pay attention to faeces they are confronted with, but invest more time in sniffing their conspecifics' faeces than their own. Low sniffing times at sheep faeces and soil heaps correspond with sniffing own faeces and indicate that the elongated sniffing at other faecal samples is not triggered by the novelty of the smell but rather by the interest in other horses' faeces. However, differences in sniffing faeces from other horses of the same group, and from unfamiliar horses with the opposite as well as the same sex were not significant. But horses paid most attention to horses from the same sex, which corresponds with earlier findings (in stallions: Stahlbaum and Houpt 1989, Rubenstein and Hack 1992, in mares and foals: Hothersall et al. 2010).

Furthermore, in the Individual Experiment, the interest a horse shows in the faeces of a group mate corresponds to the level of aggression it receives from that horse. The more aggressions they receive from the respective horse the more they sniff its faeces. In group 1, the horses' individual sniffing responses are positively related with individual levels of aggressive behaviour displayed among particular pairs of horses. The horses were particularly aggressive to specific group members, but none of the horses had an elevated aggression level in general. In group 2, one horse significantly received most sniffing responses and was particularly aggressive towards all the other group mates. Here the number of sniffing responses received show a significant linear relationship to the total number of displayed aggressions towards particular horses. Horses may be interested in potential competitors, and the amount of displayed aggression may indicate the level of social competition between particular horses. This is in line with the studies in which more intense investigation was reported for social cues from unknown individuals of the same sex (Stahlbaum and Houpt 1989, Rubenstein and Hack 1992, Hothersall et al. 2010).

The first hypothesis, that horses can discriminate the group membership and the sex of faecal donors, is not fully supported by this study but the results do not contradict previous studies. Horses clearly discriminated their own faeces from those of their conspecifics, but made no clear distinction between the sexes, or between familiar and unfamiliar donors. However, we have to note that the failure to demonstrate these distinctions in this study does not necessarily mean that horses cannot discriminate sex and familiarity by sniffing faeces. Our results may have been affected by the fact that horses may have encountered "lefto- ver faeces" from unknown conspecifics at care taking areas. Additionally, most horses from the Social Experiment were kept in social groups for only 6 months and were stabled individually over night. As has been shown by habituation-discrimination experiments (e.g. Thor and Hollloway 1982, Hothersall et al. 2010) the intensity of sniffing at social cues diminishes with the frequency of presentation. As individually stabled horses would have previously encountered their own faeces most frequently, we would expect them to sniff their own faeces least during the experiment. The faeces from familiar horses, (i.e. those with which they were turned out) would be sniffed for longer, and the faeces from unfamiliar horses, they only occasionally encountered before, would be sniffed most during the experiment. Results that match the expected discrimination of sex and familiarity may be gained by using faeces from unknown horses kept in separate locations and testing horses that are stabled in social groups day and night. Additionally, the analysis of social recognition of faecal samples may gain robustness by adding behavioural parameters to future studies (for example flehmen responses: Marinier et al. 1988). In this regard, we may point to an earlier study (Krueger and Heinze 2008), in which the majority of the horses from the Social Experiment were used and demonstrated behavioural responses indicating social recognition.

Hypothesis two, on the horse's ability to discriminate individual group mates by the smell of their faeces, is supported. We suggest that the positive linear relationship between invested sniffing time and received aggressions from specific faecal donors indicates that horses recognize potential competitors among group mates from the smell of their faeces.

It could be expected that increased display of aggressive behaviour would result in lower sniffing responses, as the "basic social recognition paradigm" claims that more social contact should result in lower investigation time. However aggressive behaviour is only a small portion of the total social behaviour horses display among each other. Horses live in typical socalled "small world networks" in which all members interact directly with each other on a roughly equal ratio (Krueger et al. in prep., Watts and Strogatz 1998, Croft et al. 2008). The display of socio-positive behaviour (approaches, mutual approaches and grooming) and socio-negative behaviour (aggressions and retreats) differs among pairs of horses, but taken together all social behaviours are displayed on an approximately even level among the members of a social group. Therefore the number of exchanged behaviours between group members does not necessarily vary, but the quality does, and this may provide the basis for the discrimination between competitors and preferred group members.

The horses from the Individual Experiment were kept in social groups day and night. For horses that are 
constantly kept together, habituation to repeatedly encountered social cues would be expected to result in equal sniffing times at their own and their group mates' faeces. This may account for the fact that the differences between sniffing own and familiar faeces were low in the Individual Experiment compared to the Social Experiment, where most of the horses were stabled separately over night. Some horses from the Individual Experiment even sniffed their own faeces longest. However, analysis of the effects of previous experiences with particular group members on sniffing times will only be feasible when all group members are equally habituated to all social cues.

For both experiments the horse's sniffing behaviour is not affected by the horse's sex, social rank, age, the day (repetition), or, in general, the position of the faeces. The social rank has been calculated from the group members' aggressive interactions as well as from their approach behaviour (please see: method section). This explains why there is a significant linear relationship between sniffing duration and aggressive behaviour, but not with the social rank, of the horses. The lack of preference for specific positions indicates that the horses from this study were not strongly affected by position or side bias effects when sniffing faeces (see for review: Mandal et al. 2000). To check for a possible visual effect, we conducted a control experiment using soil samples instead of faeces because the limited visual acuity of horses (Timney and Keil 1992) could have resulted in confusion between faeces and soil heaps of similar size, shape and colour. We also controlled for other olfactory cues generally present in faeces, such as fatty acids, alcohols, aldehydes, phenols, amines and alkanes, by exchanging the horse faeces with sheep faecal samples. To conclude, horses are similarly attracted to own faeces, sheep faeces and soil heaps, and therefore by visual and olfactory cues. But, in contrast to their behaviour while sniffing horse faeces, there is no difference between the times spent on specific samples. This suggests that either cues for the identification of specific samples are missing in soil heaps and sheep faeces, or that horses realise that the perceived cues are of no particular importance to them.

Variances in the overall correlation between sniffing times and aggressive behaviour may be due to individual likes and dislikes as well as social hierarchies. These effects may be most apparent for the lowest ranking horses, which usually avoid displaying aggressive behaviour, as well as for top ranking horses, which seldom receive aggressive actions and often do not have to compete for resources. Thus, for high ranking animals the cost of aggressive actions may outweigh the benefits (Pusey and Packer 2003, Flack at al. 2005). On the other hand, dominant animals need to invest in affiliation behaviour for the maintenance of social bonds (Aureli and de Waal 2000, de
Waal and Tyack 2003).

Finally, as horses have been reported to be sensitive to changes in the mimic and gesture of humans (Pfungst 1907, Proops et al. 2010) and orientate on human attention (Proops and McComb 2010, Krueger et al. 2010) the behaviour of the horses may have been biased by unconscious cues that were given by a partially blind experimenter when redirecting the horses towards the samples they did not sniff before. The extra leadings to non-sniffed faeces were applied because some horses were distracted from sniffing faeces by occurrences outside the experimental set-up. Additionally, horses may have been distracted by the experimenters' lack of attention to the faecal samples, in line with horses that adjust to the focus of attention of turned away experimenters in a previous study. However, we tried to avoid influencing the horses for sniffing faeces of particular donors by not telling experimenter 1 the order of the faecal samples, and by instructing the experimenter to face a predetermined point when leading the horse to the samples. Additionally, all horses needed "extra-leadings", which provided all horses with similar cues.

The physiological mechanisms of olfactory recognition through faeces are, as yet, unknown. The relevant substances could either be (1) non-volatile or (2) volatile. The first could act as primer and the latter as releaser (Kimura 2001). Volatile substances, especially fatty acids (Kimura 2001), may be of central importance. However, it appears to be noteworthy, that equids have repeatedly been described as showing intense interest in faecal samples that have been excreted many days or even weeks before (Klingel 1972, Saslow 2002, King and Gurnell 2007), which calls for considering non-volatile substances as well. Additionally, the memorisation of different scents may be affected by differing diets. We counteracted this by testing horses on similar diets for the present study. Furthermore, the horses from group 1 in this study showed an individual positive relationship between sniffing times at faeces and received aggressions from particular horses. This suggests that their discriminative abilities cannot be explained by a possible steroid hormone level connected to the horses' aggressive behaviour, and thus the social position, alone (see for review: Mormède et al. 2007).

Many social species use olfaction to distinguish the sex and familiarity of social scents, such as ants (Dreier et al. 2007), honey bees (Pesenti 2008), insects in general (Howard and Blomquist 2005), and sticklebacks (Mehlis et al. 2008). Here social recognition does not necessarily assume cognitive mechanisms and may operate on the basis of habituation processes in most species. However for individual recognition in social species with permanently changing group memberships and reproductive strategies (i.e. fission-fusion societies, hyenas: Smith et al. 
2008, dolphins: Connor et al. 2000, zebras: Fischhoff et al. 2007, horses: Proops et al. 2009) updating templates for social cues and their representation of individuals, as well as their rank and reproductive status, is permanently needed (Sherman et al. 2003). This requires cognitive capacities for permanent, flexible learning and for the memorising of the relevant social cues (Paz-y Miño et al. 2004, Allen 2006, Moses et al. 2006).

In the future, it will be worthwhile investigating the horse's olfactory individual recognition abilities further by conducting behavioural experiments and considering the crucial faecal components, their genetic expression, transportation to the gastrointestinal tract, excretion into and transportation through the gut, as well as the mechanism of olfactory recognition in horses. It may also be interesting to control for possible effects of kinship on the olfactory recognition. Even though mature horses disperse from their natal group in most cases, kin based recognition could still take place.

\section{Acknowledgements}

We wish to thank Katherine Albro Houpt for discussions on horses' dominance relationships, Christine Nicol for discussing the scientific background, Juergen Heinze and Bernd Kramer for helpful suggestions, Elisabeth D'Antoni and Kate Farmer for language corrections, Knut Krüger for the analysis in "R statistical environment" and all the owners of the horses who allowed us to test their horses and even helped with the tests. The study was supported by an HWP II grant of the University of Regensburg, an Excellence grant of the Bavarian Government and a habilitation grant of the Dr. Peter Deubner Stiftung. We declare that the experiments comply with the current laws of the country in which they were performed.

\section{References}

Acuna BD, Sanes JN, Donoghue JP (2002) Cognitive mechanisms of transitive inference. Exp Brain Res 146, 1-10. doi:10.1007/s00221-002-1092-y

Alexander F (1954) Some observations on general anaesthesia in ponies. J Comp Pathol 64, 20-25.

Allen C (2006) Transitive inference in animals: Reasoning or conditioned associations? In: Hurley S, Nudds M (eds) Rational Animals? Oxford University Press, Oxford, pp 175-186.

Arakawa H, Arakawa K, Blanchard DC, Blanchard RJ (2008) A new test paradigm for social recognition evidenced by urinary scent marking behavior in C57BL/6J mice. Behav Brain Res 190, 97-104. doi:10.1016/j.bbr.2008.02.009

Aureli F, de Waal FBM (2000) Natural conflict resolution. University of California Press. Berkeley.
Basile M, Boivin S, Boutin A, Blois-Heulin C, Hausberger M, Lemasson A (2009) Socially dependent auditory laterality in domestic horses (Equus caballus). Anim Cogn 12, 611-619. doi:10.1007/ s10071-009-0220-5

Bates LA, Sayialel KN, Njiraini NW, Poole JH, Moss CJ, Byrne RW (2008) African elephants have expectations about the locations of out-of-sight family members. Biol Lett 4, 34-36. doi:10.1098/ rsbl.2007.0529

Berger J (1977) Organizational systems and dominance in feral horses in the Grand Canyon. Behav Ecol Sociobiol 2, 131-146. doi:10.1007/ BF00361898

Berger J (1986) Wild Horses of the Great Basin: Social Competition and Population Size. University of Chicago Press, Chicago.

Brennan PA (2004) The nose knows who's who: chemosensory individuality and mate recognition in mice. Horm Behav 46, 231-240. doi:10.4141/ A00-068

Brennan PA, Kendrick KM (2006) Mammalian social odours: attraction and individual recognition. Phil Trans Biol Sci 361, 2061-2078. doi:10.1098/ rstb.2006.1931

Cheney DL, Seyfarth RM (1990) How monkeys see the world: Inside the mind of another species. University of Chicago Press, Chicago.

Clutton-Brock TH (1974) Primate social organisation and ecology. Nature 250, 539-542. doi:10.1038/250539a0

Connor RC, Wells RS, Mann J, Read AJ (2000) The bottlenose dolphin: Social relationships in a fission-fusion society. In: Mann J, Connor RC, Tyack PL, Whitehead H (eds) Cetacean Societies: Field Studies of Dolphins and Whales. University of Chicago Press, Chicago, pp 91-126.

Dawkins R (1982) The Extended Phenotyp. WH Freeman, San Francisco, California.

de Waal FB, Tyack P (2003) Animal Social Complexity: Intelligence, Culture, and Individualized Societies. Harvard University Press, Cambridge, Massachusetts.

Denniston RH (1979) The varying role of the male in feral horses. Symp Ecol and Behav of wild and feral Equids, Laramie, 93-98.

Dreier S, van Zweden JS, D'Ettorre P (2007) Longterm memory of individual identity in ant queens. Biol Lett 3, 459-462. doi:10.1098/rsbl.2007.0224

Duncan P (1992) Zebras, asses, and horses. Kelvyn Press, Broadview, Illinois.

Eisenberg JF, Kleiman DG (1972) Olfactory Communication in Mammals. Annu Rev Ecol Systemat 3, 1-32. doi:10.1146/annurev.es.03.110172.000245

Feh C (1999) Alliances and reproductive success in Camargue stallions. Anim Behav 57, 705-713. doi:10.1006/anbe.1998.1009 
Feh C (2001) Alliances between stallions are more than just multimale groups: reply to Linklater \& Cameron (2000). Anim Behav 6, F27-F30. doi:10.1006/anbe.1998.1009

Feh C (2005) Relationships and Communication in Socially Natural Horse Herds. In: Mills DS, McDonnell S. M. (eds) The domestic horse : the origins, development, and management of its behaviour. Cambridge University Press 2005, Cambridge.

Feist JD, McCullough DR (1976) Behavior patterns and communication in feral horses. Z Tierpsychol 41, 337-371.

Flack JC, de Waal FBM, Krakauer DC (2005) Social structure, robustness, and policing cost in a cognitively sophisticated species. Am Nat 165, E12639. doi:10.1086/429277

Franke Stevens E (1988) Contents between bands of feral horses for access to fresh water: the resident wins. Anim Beh 36, 1851-1853. doi:10.1016/ S0003-3472(88)80132-5

Goldschmidt-Rothschild VB, Tschanz B (1978) Soziale Organisation und Verhalten einer Jungtierherde beim Camargue-Pferd. Z Tierpsychol 46, 372-400.

Gosling LM, Roberts SC (2001) Testing ideas about the function of scent marks in territories from spatial patterns. Anim Behav 62, F7-F10. doi:10.1006/ anbe.2001.1802

Hemelrijk CK, Wantia J, Gygax L (2005) The construction of dominance order: comparing performance of five methods using an individual-based model. Behaviour 142, 1043-1064. doi:10.1163/156853905774405290

Hothersall B, Harris P, Sörtoft L, Nicol C (2010). Discrimination between conspecific odour samples in the horse (Equus caballus). Appl Anim Behav Sci. 126, 37-44. doi:10.1016/j.applanim.2010.05.002

Howard RW, Blomquist GJ (2005) Ecological, behavioral, and biochemical aspects of insect hydrocarbons. Annu Rev Entomol 50, 371-393. doi:10.1146/annurev.ento.50.071803.130359

i Rios JF, Houpt K (1995) Sexual behavior in geldings. Appl Anim Behav Sci 46, 133-135.

Keiper R (1976) Social organization of feral ponies. Proc Pennsyl Acad Sci 50, 69-70.

Kiley M (1972) The vocalizations of ungulates, their causation and function. Z Tierpsychol 31, 171222.

Kimura R (2001) Volatile substances in feces, urine and urine-marked feces of feral horses. Can J Anim Sci 81, 411-420. doi:10.4141/A00-068

King SRB (2002) Home range and habitat use of free-ranging Przewalski horses at Hustai National Park, Mongolia. Appl Anim Behav Sci 78, 103113. doi:10.1016/S0168-1591(02)00087-4
King SRB, Gurnell J (2007) Scent-marking behaviour by stallions: an assessment of function in a reintroduced population of Przewalski horses (Equus ferus przewalskii). J Zool 272, 30-36. doi:10.1111/ j.1469-7998.2006.00243.x

Klingel H (1972) The behavior of horses (Equidae). Handb Zoolog 8, 1-68.

Krueger K, Heinze J (2008) Horse sense: social status of horses (Equus caballus) affects their likelihood of copying other horses' behavior. Anim Cogn 11, 431-439. doi:10.1007/s10071-007-0133-0

Krueger K, Flauger B, Farmer K, Maros K (2010). Horses ( Equus caballus ) use human local enhancement cues and adjust to human attention. Anim Cogn doi:10.1007/s10071-010-0352-7

Lemasson A, Boutin A, Boivin S, Blois-Heulin C, Hausberger M (2009) Horse (Equus caballus) whinnies: a source of social information. Anim Cogn 12, 693-704. doi:10.1007/s10071-0090229-9

Levy F, Keller M, Poindron P (2004) Olfactory regulation of maternal behavior in mammals. Horm Behav 46, 284-302. doi:10.1016/j.yhbeh.2004.02.005

Ligout S, Porter R-H (2006) Social recognition in mammals: Mechanisms and sensorial bases. Prod Anim 19, 119-133.

Lindsay FE, Burton FL (1983) Observational study of "urine testing" in the horse and donkey stallion. Equine Vet J 15, 330-336.

Linklater WL (2000) Adaptive explanation in socioecology: lessons from the Equidae. Biol Rev Camb Philos Soc 75, 1-20.

Linklater WL, Cameron EZ (2000) Tests for cooperative behaviour between stallions. Anim Behav 60, 731-743. doi:10.1006/anbe.2000.1525

Linklater WL, Cameron EZ, Minot EO, Stafford KJ (1999) Stallion harassment and the mating system of horses. Anim Behav 58, 295-306. doi:10.1006/ anbe.1999.1155

Linklater WL, Cameron EZ, Stafford KJ, Veltman CJ (2000) Social and spatial structure and range use by Kaimanawa wild horses (Equus caballus: Equidae). New Zealand J Ecol 24, 139-152.

Malmgren L, Andresen Ø, Dalin A-M (2001) Effect of $\mathrm{GnRH}$ immunisation on hormonal levels, sexual behaviour, semen quality and testicular morphology in mature stallions. Equine vet $\mathrm{J} 33,75-83$.

Mandal MK, Bulman-Fleming MB, Tiwari G (2000) Side Bias: A Neuropsychological Perspective. Springer, Netherlands.

Marinier SL, Alexander AJ, Waring GH (1988) Flehmen behaviour in the domestic horse: Discrimination of conspecific odours. Appl Anim Behav Sci 19, 227-237. doi:10.1016/0168-1591(88)90003-2

Mateo JM (2006) The nature and representation of individual recognition odours in Belding's ground squirrels. Anim Behav 71, 141-154. doi:10.1016/j. anbehav.2005.04.006 
McCullough P, Nelder JA (1989) Generalized linear models. Chapman \& Hall, New York.

McDonnell SM (2003) The Equid Ethogram: A Practical Field Guide to Horse Behavior. Eclipse Press, Lexington, Kentucky.

McDonnell SM, Haviland JCS (1995) Agonistic ethogram of the equid bachelor band. Appl Anim Behav Sci 43, 147-188. doi:10.1016/01681591(94)00550-X

Mehlis M, Bakker T, Frommen J (2008) Smells like sib spirit: kin recognition in three-spined sticklebacks ( Gasterosteus aculeatus ) is mediated by olfactory cues. Anim Cogn 11, 643-650. doi:10.1007/ s10071-008-0154-3

Miller R (1981) Male aggression, dominance and breeding behaviour in Red Desert feral horses. Z Tierpsychol 57, 340-201.

Moehlman PD (2002) Equids: zebras, asses and horses: status survey and conservation action plan. IUCN, Gland, Switzerland.

Moehlman PD (2005) Endangered wild equids. Sci Am 292, 74-81.

Mormède $P$, Andanson $S$, Aupérin $B$, Beerda $B$, Guémené D, Malmkvist J, Manteca X, Manteuffel G, Prunet P, van Reenen CG, Richard S, Veissier I (2007) Exploration of the hypothalamic-pituitaryadrenal function as a tool to evaluate animal welfare. Physiol Behav 92, 317-339. doi: 10.1016/j. physbeh.2006.12.003

Moses SN, Villate C, Ryan JD (2006) An investigation of learning strategy supporting transitive inference performance in humans compared to other species. Neuropsychologia 44, 1370-1387. doi:10.1016/j.neuropsychologia.2006.01.004

Moss CJ, Poole JH (1983) Relationships and social structure in African elephants. In: Hinde RA (ed) Primate social relationships: an integrated approach. Blackwell Science Ltd,.

Murphy J, Arkins S (2007) Equine learning behaviour. Behav Process 76, 1-13. doi:10.1016/j.beproc.2006.06.009

Nelder JA, Wedderburn RWM (1972) Generalized Linear Models. J Roy Statist Soc A 135, 370-384.

Nicol CJ (2002) Equine learning: progress and suggestions for future research. Appl Anim Behav Sci 78, 193-208. doi:10.1016/S0168-1591(02)00093$\mathrm{X}$

Patris B, Perrier G, Schaal B, Coureaud G (2008) Early development of filial preferences in the rabbit: implications of nursing- and pheromone-induced odour learning? Anim Behav 76, 305-314. doi:10.1016/j.anbehav.2008.01.017

Paz-Y-Mino C. G., Bond AB, Kamil AC, Balda RP (2004) Pinyon jays use transitive inference to predict social dominance. Nature 430, 778-781. doi: 10.1038/nature02723

Penn D, Potts WK (1998) Untrained mice discriminate MHC-determined odors. Physiol Behav 64, 235-243. doi:10.1016/S0031-9384(98)00052-3
Pesenti ME, Spinelli S, Bezirard V, Briand L, Pernollet J-C, Tegoni M, Cambillau C (2008) Structural Basis of the Honey Bee PBP Pheromone and $\mathrm{pH}-$ induced Conformational Change. J Mol Biol 380, 158-169. doi:10.1016/j.jmb.2008.04.048

Pfungst O (1907) Der Kluge Hans. Ein Beitrag zur nichtverbalen Kommunikation. Frankfurter Fachbuchhandlung für Psychologie, Frankfurt am Main.

Proops L, McComb K, Reby D (2009) Cross-modal individual recognition in domestic horses (Equus caballus). PNAS 106, 947-951. doi:10.1073/ pnas.0809127105

Proops L, McComb K. (2010) Attributing attention: the use of human-given cues by domestic horses ( Equus caballus ). Anim Cogn 13(2), 197-205. doi:10.1007/s10071-009-0257-5

Proops L, Walton M, McComb K (2010) The use of human-given cues by domestic horses, Equus caballus, during an object choice task. Anim Behav 79(6), 1205-1209. doi:0.1016/j.anbehav.2010.02.015

Pusey AE, Packer C (2003) The Ecology of relationships. In: Krebs JR, Davis NB, (ed) Behavioural Ecology. Blackwell Scientific Publication, Oxford, pp 254-283.

Roberts J, Kacelnik A, Hunter ML (1979) A model of sound interference in relation to acoustic communication. Anim Behav 27, 1271-1273.

Rubenstein DI, Hack MA (1992) Horse signals: The sounds and scents of fury. Evol Ecol 6, 254-260. doi:10.1007/BF02214165

Rubenstein DI (1986) Ecology and sociality in horses and zebras. In: Rubenstein DI, Wrangham RW (eds) Ecological Aspects of Social Evolution. Princeton University Press, Princeton, NJ., pp 282-302.

Rutberg AT (1990) Inter-group transfer in assateague pony mares. Anim Behav 40, 945-952. doi:10.1016/S0003-3472(05)80996-0

Rutberg AT, Greenberg SA (1990) Dominance, aggression frequencies and modes of aggressive competition in feral pony mares. Anim Behav 40, 322-331

Rutberg AT, Keiper RR (1993) Proximate causes of natal dispersal in feral ponies: some sex differences. Anim Behav 46, 969-975.

Rydhmer L, Lundström K, Andersson K (2010) Immunocastration reduces aggressive and sexual behaviour in male pigs. Anim 4, 965-972. doi:10.1017/ S175173111000011X

Saslow CA (2002) Understanding the perceptual world of horses. Appl Anim Behav Sci 78, 209224. doi:10.1016/S0168-1591(02)00092-8

Scordato ES, Drea CM (2007) Scents and sensibility: information content of olfactory signals in the ringtailed lemur, Lemur catta. Anim Behav 73, 301314. doi:10.1016/j.anbehav.2006.08.006 
Seyfarth RM, Cheney DL (2003) The Structure of Social Knowledge in Monkeys. In: de Waal T (ed) Animal Social Complexity: Intelligence, Culture, and Individualized Societies. Harvard University Press, Cambridge, Massachusetts.

Shaw EB, Houpt KA, Holmes DF (1988) Body temperature and behaviour of mares during the last two weeks of pregnancy. Equine Vet J 20, 199-202

Sherman PW, Reeve HK, Pfenning DW (2003) Recognition Systems. In: Behavioural Ecolgy (eds).: JR Krebs and NB Davis), Blackwell Publishing, Oxford, 69-96.

Smith JE, Kolowski JM, Graham KE, Dawes SE, Holekamp KE (2008) Social and ecological determinants of fission-fusion dynamics in the spotted hyaena. Anim Behav 76, 619-636. doi:10.1016/j. anbehav.2008.05.001

Stahlbaum CC, Houpt KA (1989) The role of the Flehmen response in the behavioral repertoire of the stallion. Physiol Behav 45, 1207-1214. doi:10.1016/0031-9384(89)90111-X

Stoddart DM (1980) The ecology of vertebrate olfaction. Chapman and Hall, London; New York.

Thor DH, Holloway WR (1982) Social memory of the male laboratory rat. J Comp Physiol Psychol 96, 1000-1006.

Stone SM (2010) Human facial discrimination in horses: can they tell us apart. Anim Cogn 13, 51-61. doi:10.1007/s10071-009-0244-x

Tibbetts EA (2002) Visual signals of individual identity in the wasp Polistes fuscatus. Proc Roy Soc Lond B Biol Sci 269, 1423-1428. doi:10.1098/ rspb.2002.2031

Tilson RL, Sweeny KA, Binczik GA, Reindl NJ (1988) Buddies and bullies: social structure of a bachelor group of Przewalski horses. Appl Anim Behav Sci 21, 169-185.
Timney B, Keil K (1992) Visual acuity in the horse. Vis Res 32, 2289-2293. doi:10.1016/00426989(92)90092-W

Treichler FR, Van Tilburg D (1996) Concurrent Conditional Discrimination Tests of Transitive Inference by Macaque Monkeys: List Linking. J Exp Psychol Anim Behav Process 22, 105-117. doi:10.1037/0097-7403.22.1.105

Trillmich F, Rehling A (2006) Animal Communication: Parent-Offspring. In: Keith Brown (ed) Encyclopedia of Language \& Linguistics. Elsevier, Oxford, pp 284-288.

Tyler SJ (1972) The behaviour and social organisation of the new Forest ponies. Anim Behav Monogr 5, 85-196.

Veissier I, Boissy A, Nowak R, Orgeur P, Poindron P (1998) Ontogeny of social awareness in domestic herbivores. Appl Anim Behav Sci 57, 233-245. doi:10.1016/S0168-1591(98)00099-9

Vinke CM, van Deijk R, Houx BB, Schoemaker NJ (2008) The effects of surgical and chemical castration on intermale aggression, sexual behaviour and play behaviour in the male ferret (Mustela putorius furo). Appl Anim Behav Sci 115, 104-121. doi:10.1016/j.applanim.2008.05.003

Waldmann B (1991) Kin recognition in amphibians. In: Kin Recognition (ed. P. Hepper), Cambridge University Press, Cambridge, 162-219.

Waring GH (1983) Horse Behaviour: The Behavioural Traits and Adaptations of Domestic and Wild Horses, Including Ponies. Noyes, Park Ridge, NJ. Wilson O E (1975) Sociobiology: The new Synthesis. Belknap Press, Cambridge. 